\title{
CORRIGENDA
}

\section{EMQN Best Practice Guidelines for molecular and haematology methods for carrier identification and prenatal diagnosis of the haemoglobinopathies}

Joanne Traeger-Synodinos, Cornelis L Harteveld, John M Old, Mary Petrou, Renzo Galanello, Piero Giordano, Michael Angastioniotis, Barbara De la Salle, Shirley Henderson and Alison May on behalf of contributors to the EMQN haemoglobinopathies best practice meeting

\section{European guidance for the molecular diagnosis of pseudohypoparathyroidism not caused by point genetic variants at GNAS: an EQA study}

Intza Garin, Giovanna Mantovani, Urko Aguirre, Anne Barlier, Bettina Brix, Francesca M Elli, Kathleen Freson, Virginie Grybek, Benedetta Izzi, Agne's Linglart, Guiomar Perez de Nanclares, Caroline Silve, Susanne Thiele and Ralf Werner on behalf of the EuroPHP Consortium

European Journal of Human Genetics (2015) 23, 560; doi:10.1038/ejhg.2015.40

Correction to: European Journal of Human Genetics advance online publication, 9 July 2014; doi:10.1038/ejhg.2014.127
This article has been amended to 'Policy' since online publication. The corrected paper appears in this issue. 